\title{
COVID-19 effects on municipality waste collection services for households: statistical modelling of perspectives from Guyana and Nigeria
}

\author{
Stephan Moonsammy ${ }^{1}$ (D) Temitope D. Timothy Oyedotun ${ }^{2} \cdot$ Donna-Marie Renn-Moonsammy $^{3}$. \\ Temitayo Deborah Oyedotun ${ }^{4} \cdot$ Nasrudeen Ally $^{2}$. Oluwasinaayomi Faith Kasim ${ }^{2}$ - Ayomide Famewo ${ }^{5}$
}

Received: 24 November 2020 / Accepted: 31 March 2021 / Published online: 9 April 2021

(c) Springer Japan KK, part of Springer Nature 2021

\begin{abstract}
The novel COVID-19 pandemic has disrupted the functioning of solid waste management globally as households experience an increase in their waste and a change in waste collection services. This study presents a statistical model looking at the impacts of COVID-19 on household waste and waste collection services and the prevalence of self-disposing in response to these impacts. Qualitative household data were collected from Guyana and Nigeria looking at household perspectives on their waste management issues since the emergence of COVID-19. Statistical models were developed using limiteddependent binary logistic regression. The models showed for each country, different factors contributing to the likelihood of self-disposing. For Guyana, the change in waste collection schedule and the household proximity to landfills increases the likelihood of self-disposing while in Nigeria, the increase in household waste increases the likelihood of self-disposing. The results also showed that households who regularly engage in recycling activities are less likely to self-dispose. The study concludes that COVID-19 has disrupted household waste disposal and had contributed to increasing instances in selfdumping. COVID-19 seems to be fostering the informal waste sector which may require a shift in the current operation and policies for the solid waste management sector.
\end{abstract}

Keywords COVID-19 $\cdot$ Informal waste sector $\cdot$ Municipal solid waste $\cdot$ Self-disposing

Stephan Moonsammy

stepahn.moonsammy@uog.edu.gy

$\triangle$ Temitope D. Timothy Oyedotun temitope.oyedotun@uog.edu.gy

1 Department of Environmental Studies, Faculty of Earth and Environmental Sciences, University of Guyana, Turkeyen Campus, P. O. Box 10 1110, Georgetown, Guyana

2 Department of Geography, Faculty of Earth and Environmental Sciences, University of Guyana, Turkeyen Campus, P. O. Box 10 1110, Georgetown, Guyana

3 Pensa Fuori Concepts \#4 Parakeet Street, Trincity, Trinidad and Tobago

4 Faculty of Education and Humanities, University of Guyana, Turkeyen Campus, P. O. Box 10 1110, Georgetown, Guyana

5 Department of Urban and Regional Planning, University of Ibadan, Ibadan, Nigeria

\section{Introduction}

The novel Sars-Cov-2 virus commonly known as COVID-19 and the subsequent government policies to prevent its spread has caused the disruption of numerous public services globally including the collection and management of municipal solid waste [39]. Several studies have shown that there are two main reasons for the disruption of municipal solid waste caused by the COVID-19 pandemic. First, the pandemic has caused a rapid increase in medical solid waste and secondly, the disruption of regular municipality solid waste collection services as countries implement variations of "hard lockdown' policies restricting everyday activities [11, 26, 39]. The proliferation of medical waste and disruption of waste collection services has created a relatively unnoticed environmental catastrophe. As much attention is given to dealing with the immediate contagion transmission of COVID-19, reports have shown surges in medical waste in municipalities further exacerbating the contagion and spread of other infectious diseases [39]. Municipalities across the disease's first 
epicentre in China showed after 4 months of the pandemic, solid waste disposal increased from 4900 tonnes/day to 6000 tonnes/day [8]. Municipalities in Ontario Canada showed up to a $5 \%$ increase in garbage collected during March and April in 2020 when compared to volumes collected for the same months in 2019 [40]. Municipalities in Singapore reported similar trends as Ontario estimating a 3\% increase in garbage collected daily since April 2020 [15].

According to van Fan et al. [41], COVID-19 has impacted solid waste management globally by changing the volume of waste, changing the composition of waste, changing the distribution of waste, changing the disposal frequency and changing the safety and infections risks associated with the composition of the waste. Furthermore, the changes outlined by van Fan et al. [41] subsequently resulted in new challenges faced in the processes of collection, treatment, recycling, landfill allocations and safety protocols of the municipal solid waste management system of countries. Singh et al. [39] highlighted that the impacts on the lifestyle and socioeconomic context of households due to COVID-19 are determining factors linked to the challenges presently faced by municipal solid waste management globally. Nzeadibe and Madu [27] outlined that disease outbreaks with far-reaching implications often result in uncontrolled piles of solid waste within communities further exacerbating the public health crisis. The COVID-19 pandemic has disrupted the household garbage collection processes for many countries globally. Countries have opted to reduce the frequency of garbage collection by municipal waste collectors primarily as a means of containing the disease spread. Garbage collectors were identified as a potential vector for spreading COVID-19 as they will regularly contact contaminated medical waste [23, 41]. Kulkarni and Anantharama [12], recommended that waste collection should be reduced and decentralized to a community level to minimize the impacts of COVID-19 spreading between communities through the waste collection processes. Pentaeado and Soares de Castro [32] documented that waste organizers in Brazil identified waste pickers, collectors and persons frequenting the landfills as a vulnerable group susceptible to contracting COVID-19 through contact with contaminated medical waste in landfills. With Brazil's surge in COVID-19 cases and deaths, the municipal authorities responded to the concerns of contamination from waste by reducing collection services and reducing staff at landfills and sorting facilities.

The issue of solid waste management in the era of COVID-19 has forced policymakers to re-think the practices adopted within their municipal solid waste management plan [2]. Most notably, a widening disparity can be observed between the approach of developed countries and the approach of developing and less developed countries [12, 21-24]. Before COVID-19, the literature shows a prevalence of an informal solid waste management sector in developing and less developed countries whose activities are unsponsored, unregulated, disorganized, lack safety protocols and often illegal [4, 30, 43]. The informal solid waste management sector often includes self-disposal, foragers and scavengers and private waste collectors for hire $[6,7,16,31,42,45]$. With the COVID-19 pandemic, the prevalence of the informal sector in some countries presents a new challenge in managing the spread from solid waste $[11,35]$. While several studies are looking at the social, economic, cultural and environmental dynamics behind the informal solid waste management sector $[1,4,25,36$, 43], not much work has been done exploring the informal sector amidst the COVID-19 pandemic. According to van Fan et al. [41], COVID-19 restrictions on employment and schools have caused an increase in household waste and a decrease in business and industrial waste since people are spending more time at home. This increase in household waste coupled with COVID-19 restrictions on the municipal solid waste system can stimulate activeness in the informal sector in many ways. The reduction in collection services and an increase in household waste can see more households self-disposing. The increase in the volume of waste can lure more foragers, scavengers and private collectors as well. This study intends to empirically explore the impacts of COVID-19 on the informal waste sector. The empirical observations were conducted in the developing countries of Guyana and Nigeria. Where the informal solid waste sector is well documented in Nigeria [1,27-29], the literature was limited for Guyana. Recent research conducted in both countries does demonstrate a definitive impact on the solid waste dynamics in both countries by COVID-19 with a notable increase in household waste stemming from the lockdown measures implemented [30].

The practice of self-disposal and other informal waste sectors may have accelerated with the changing dynamics of solid waste management caused by COVID-19 but the practices in countries like Guyana and Nigeria can be attributed to waste management sector on a hold. In Guyana, waste collection is a free public good overseen by the City Councils and often by state hired contract collectors [34, 47] whereas, in Nigeria, waste collection is also a free public good overseen by state and local governmental environmental agencies [29]. In both countries, the predominant waste system is landfill based whereby municipal waste collectors on scheduled routes collects household waste and disposes of it at a state-controlled landfill. Similarly, both systems are challenged with funding resources as most of the funding comes from state budgetary allocations which have to pay recurring expenditures and also budget for developmental works. The lack of resources to the municipal services has often resulted in inefficient collection services, especially for rural communities who receive fewer services and environmental issues stemming from a lack of landfill upkeep, 
limited facilities for recycling and a lack of public awareness programs on waste reduction [29, 34, 47]. The literature also shows the prevalence of informal recycling in both countries $[1,25,30,34]$ which typically stems from a waste management system with low standards in regulations and policy enforcement [4]. This informal recycling sector has a negative social and economic stigma and is often associated with poor working conditions, poverty, child labor and social rejection [4]. In Guyana and Nigeria, the informal recycling sector predominantly operates in the repurposing of scrap metal, electronic parts and materials for construction. The repurposing is not done within any recycling plant or industry but usually at private residents that operate small businesses from the material. These are the factors identified in the literature for developing countries that promote the prevalence of the informal waste sector $[4,25]$.

While the informal recycling sector is well documented, the issue of persons dumping their garbage is largely unexplored explicitly in the literature empirically, with more literature focusing on descriptive reporting on the issue, primarily because most self-disposal activities are normally illegal and unregulated, thus making it challenging to gather accurate data on the subject. Though not well documented empirically, the issue of household dumping waste on their own is very visible and prominent in developing countries [44]. Although many factors perpetuate self-disposal activities at a household level [17], the main factors are often due to the socio-economic conditions of the community or the quality of service provided by municipal collectors. Quite often, municipal collectors only collect garbage disposed of in bags and may refuse the disposal of larger waste items, such as furniture or electrical appliances, resulting in homeowners self-disposing these items in the landfill or rivers. The practice of self-disposal of waste is generally viewed as a wider sustainability concern [44], but with the COVID-19 pandemic, it additionally becomes a matter of fostering the disease spread. The study attempts to identify in the countries comprising the study area, the likelihood of households self-disposing waste since the COVID-19 pandemic and how municipal collection services and informal recycling influences the prevalence of self-disposing. Ikiz et al. [11] identified that no studies have attempted to determine the effects of COVID-19 on sustainable behavior at the household level in disposing of waste and if impacts are leading to possible waste diversion. Nzeadibe and Madu [27] synthesized several studies and reports in Nigeria highlighting the state of affairs of the solid waste sector as it adjusts to COVID-19 and the need to understand the socioeconomic dimension behind the solid waste sector, including the household's contribution to the prevalence of self-dumping and informal recycling. Kulkarni and Anantharama [12] postulated that a shift in the municipal solid waste system may be a direct nexus stemming out of COVID-19 and social and economic evaluations are required at the community level to better understand the policy environment needed to shift household behaviour to align with this nexus. Oyedotun et al. [30] outlined that the solid waste sector in Guyana and Nigeria is plagued with questionable practices that can potentially endanger citizens in contracting COVID-19 through solid waste contamination and there is an empirical need to explore the extent of these practices further.

Though the logical assumption based on prior solid waste literature is that a reduction in the waste collection will cause an increase in self-dumping, the statistical model presented in this paper presents an empirical base to this assumption. Additionally, establishing the relationship between household practices and the waste management system is well documented in the literature as a crucial factor in addressing the solid waste management issues amidst COVID-19 especially as the literature demonstrates the dangers of COVID19 spreading through infected wastes [32].

\section{Pre-COVID-19 solid waste management}

Effectively managing with the new paradigms of COVID-19 when it comes to solid waste depends on the pre-existing condition of the sector. The state of the solid waste management system varies according to the country. Many developed countries often employ a wider variety of waste management strategies including waste separation and collection, disposal fees, recycling incentives and public education which is supported by the necessary infrastructure, policies and regulations [19]. Poor waste management structure often results in several deleterious environmental and health impacts [33].

The situation in developing and less developed countries is not the same. Guyana and Nigeria, for instance, have a waste system predominantly offered as a public good with established but poorly maintained landfills, several unregulated dumpsites and a lack of options for collection and disposal [25, 29, 47]. In Guyana, the local municipal councils manage waste collection schedules and routes. Waste for collection by the municipal waste collectors is placed into any available containers from the households, such as barrels, large boxes, bins or drums and in some instances, garbage bags are left on the curbside in front of houses [47]. There are no regulations and policies that restrict the number of bags disposed of per household. All household wastes collected by municipal authorities are dumped in statecontrolled landfills that lack infrastructure for compaction or composting, are improperly lined and generally unmonitored [47]. Despite these challenges, Guyana has embarked on developing an integrated solid waste management plan which promises more sustainable measures for waste management including an improvement of the existing landfill infrastructure, more public education and new policies, such 
as bans or restrictions of single-use plastic bags by retailers. Recycling in the country is predominantly challenged by a lack of recycling infrastructure and policies to promote recycling activities. Presently, there is minimal waste separation especially at the household level and the majority of household garbage is disposed of collectively.

The circumstance in Nigeria is very similar to Guyana whereby state-controlled waste collection schedules and routes collect household garbage and dump it into statecontrolled landfills. The primary issue in Nigeria is the lack of finances, equipment and human resources to meet the mandates of the waste management sector. Stemming out of this capacity issue, the country has several illegal dumpsites alongside roads and river banks in both the urban and rural areas indicating an overall inefficiency in waste collection countrywide [1]. The country has embarked on policy reforms for its solid waste sector by allowing private sector participation in waste collection and renewal and exploring more comprehensive strategies for urban solid waste pollution control [25]. Despite these policy efforts, Nigeria generally lacks programs and infrastructure for waste recovery, waste separation and recycling $[25,28,30]$. The current condition of the waste sector for both countries has a myriad of challenges pre-COVID-19. Policy considerations for the waste sector of each country require a comprehensive understanding of the main facets of the industry at the municipality and household level to effectively implement measures against the pandemic $[25,30]$.

\section{Methodology}

A prior study on the impacts of COVID-19 on household waste management conducted by Ikiz et al. [11] adopted semi-structured interviews and focus groups all done online due to restrictions imposed as a result of the pandemic. This study provided a qualitative insight into some of the challenges that residents in apartment buildings face in recycling and disposing of waste since the implementation of 'lockdown' measures due to COVID-19. Though the paper could not empirically establish waste volume changes over a large extent of the 'lockdown' measure and did highlight the limitation in the diversity of homeowners tenure (mostly leased or rental tenures) that can affect the representativeness of the study, the method established did provide some insights into the waste system disruptions experienced by multi-residential buildings since COVID-19. This study builds upon the methodology established by Ikiz et al. [11] by implementing a household survey over several regions in Guyana and Nigeria to implement a more empirical analysis on household waste dynamics across a wider variety of household tenures. An online survey was administered in Guyana and Nigeria between June and July 2020, four months after the implementation of the 'hard lockdown' measures in both countries. The 'hard lockdown' measures implemented in both countries saw the closure of schools and workplaces and persons operating mainly online. The restrictions also limited movement across the countries with scheduled curfews implemented and particular communities restricting access to outsiders. As such, the surveys were circulated through emails, Facebook and what's App using a convenience sampling framework owing to the imposed lockdown in the countries. The surveys were pretested and then implemented using Google Forms and consisted of questions asking households about the volume of waste, frequency of collectors, proximity to dumping sites and if they engage in self-disposal. Respondents were asked to complete the survey to the best of their ability and also encouraged to forward the link. Though the initial link was circulated to the contacts of the research team, the researchers were unaware of the persons whom the link was forwarded too. At the end of the survey period, there were 216 complete responses from Guyana and 273 complete responses from Nigeria. To validate the statistical analytical technique adopted, a power analysis was conducted assuming a 5\% significance level and an estimated ratio of 0.45 as descriptive proportions showed approximately $40 \%$ to $50 \%$ of an affirmative response in the dependent variable based on the exogenous variables identified [46]. Power analysis $(n=211)$ showed that the sample sizes used marginally meet the minimum sample requirement.

The survey consisted of both closed qualitative questions using categorical responses including a four-point Likert scale and binary response options and open-ended qualitative questions eliciting the respondent's perception on various solid waste management issues. The data were collated and analyzed using Microsoft Excel and the Statistical Package for Social Sciences (SPSS v. 16.0).

\section{Statistical model and analysis}

With the qualitative nature of the data set, the analysis was conducted using limited-dependent regression modelling. Limited dependent modelling has been used in the literature to analyze the dynamics of self-dumping before. Ichinose and Yamamoto [10] adopted a negative binomial regression model for a panel database to empirically establish the relationship between the provision of waste treatment facilities and self-disposing. Model selection in the study by Ichinose and Yamamoto was based on the nature of the dependent variable whereby the prevalence of household self-disposing was computed as a count variable. In this paper, self-disposing was computed as a binary variable as respondents were asked whether or not they engaged in self-disposing. Due to the binary nature of the dependent variable, a binary logistic regression model (LOGIT) was implemented to calculate the 
probability of households disposing of waste themselves. The functional form of the model is expressed as:

$Y(1 \mid 0)=f\left(X_{i j}, D_{i j}\right)$

where $Y$ is a binary-dependent variable and $X_{i j}$ is a vector of numerical explanatory variables and $D_{i j}$ is a vector of qualitative dummy variables for the $i$ th individual across the jth number of observations. Our probability model is based on the standard LOGIT framework $[5,9]$ as:

$\ln (P / 1-P)=\alpha+\beta_{1}\left(X_{i j}\right)+\beta_{2}\left(D_{i j}\right)$

where $\ln (P / 1-\mathrm{P})$ is the log odds ratio of whether or not the households in the study engages in self-disposal of waste, $\alpha$ is the constant coefficient and $\beta$ are the parameter coefficients. The probability of a house engaging in self-disposal is then calculated using a natural exponential function of Eq. (2) [9].

$\operatorname{Pr}(P)=\frac{\mathrm{e}^{\alpha+\beta_{1}\left(X_{i j}\right)+\beta_{2}\left(D_{i j}\right)}}{1+\mathrm{e}^{\alpha+\beta_{1}\left(X_{i j}\right)+\beta_{2}\left(D_{i j}\right)}}$

where $\operatorname{Pr}(P)$ is the probability of self-disposing. The exogenous variables used in the LOGIT model were identified in the literature as factors that can influence households to engage in self-disposal activities and include the change in collection schedules, increase in household waste, proximity to a landfill and the municipality of their households. Probability models were developed and interpreted for Guyana and Nigeria.

\section{Results and discussion}

The study encompassed a sample comprising 489 households in the two countries with participants from 9 out of the 10 administrative regions in Guyana and from 24 out of the 36 administrative states in Nigeria. Though it was not comprehensively identified in the data, the population spread for each country shows a high rural population for both. Guyana has a rural population of approximately $73 \%$ whereas Nigeria's rural population is approximately $45 \%$.
The sample population primarily consisted of adults over 28 years old which comprised $66 \%$ of the sample with $34 \%$ falling between 18 and 27 years. In terms of the gender distribution of respondents, $68 \%$ of the respondents from Guyana were female whereas, $61 \%$ of the respondents from Nigeria were male. As it relates to household waste dynamics, $63 \%$ of the households in Guyana and 59\% of households in Nigeria indicated they observed an increase in household waste since the onset of the COVID pandemic. The household respondents indicated particular areas of concern in the present solid waste system amidst the COVID19 pandemic with an overwhelming majority of households (97\% in Guyana and $87 \%$ in Nigeria) identifying the lack of proper disposal mechanisms, lack of recycling infrastructure and inadequate waste management policies that need revising for the COVID-19 pandemic. The descriptive data show that the system presently is perceived as inadequate and inefficient by the households in both countries and can be then viewed as the primary contributing factor to potential self-dumping.

In constructing the probability models for Guyana and Nigeria, the exogenous variables used are presented in Table 1. Adapted from the literature, the variables outlined in the Table 1 were identified as possible factors that can promote self-disposal activities. For instance, Ichinose and Yamamoto [10] results showed that a shortage of waste collection and waste treatment structures directly results in more dumping. Liu et al. [14] presented a Poisson regression model whereby recycling and landfill dispersion had a significant impact on the prominence of illegal dumping. Additionally, several studies showed that households engage in recycling activities are less likely to engage in self-dumping [3, 13, 20, 38]. Matsumoto and Takeuchi [17] empirically showed that marginalized communities with inconsistent delivery services are contributing factors to illegal dumping. Sedova [37] showed higher rates of illegal dumping occurring with easier access to dumpsites, especially illegal sites. The literature shows that households respond to their circumstances and will engage in illegal or self-dumping if there is an increase in household waste, an unreliable waste collection service, poor enforcement of waste management policies and proximity to dumping sites. These factors are
Table 1 Descriptive characteristics of the exogenous variables

\begin{tabular}{ll}
\hline Variable & Description \\
\hline $\begin{array}{l}\text { Increase in household waste } \\
\text { Reduced Services }\end{array}$ & $\begin{array}{l}\text { Households observed a notable increasing household waste } \\
\text { A reduction in schedule of municipal waste collectors was observed } \\
\text { by households }\end{array}$ \\
$\begin{array}{l}\text { Proximity to Dump } \\
\text { Populous Municipality }\end{array}$ & $\begin{array}{l}\text { Household located near to an established or unregulated dumping site } \\
\text { Practice Recycling }\end{array}$ \\
\hline
\end{tabular}

Models consists of qualitative exogenous variables only 
generally identifiable even though many other underlying factors may affect self-dumping, such as the rural context, waste disposal for residential lots or apartment buildings and poverty. The variables adopted in this study expand upon those identified in the literature by measuring the statistical effect on the probability of self-dumping. All the exogenous variables were qualitative either expressed as a binary dummy variable or an ordinal dummy variable. The dummy variables were treated as intercept variables where the coefficient values were used to compute the probabilities.

The models included the variable populous municipality as these areas tend to have the largest municipal waste collection services. This variable was then interpreted as a proxy of the efficiency and enforcement of solid waste management regulations since this could not be observed from the perspectives of households. The interpretive rationale behind this variable is if there is a positive relationship between self-disposal from households in the largest municipalities, then this is an indication of underlying solid waste management issues in the country.

The data were collected with the households understanding that the context of the questions was related to the present circumstances with COVID-19. Table 2 presents the household responses to the change in household solid waste management since the emergence of the COVID-19 pandemic.

More than half of the households for both Guyana and Nigeria noticed an increase in household waste since the 'hard lockdown' measures with a similar proportion for both countries indicating that household waste volume has doubled during this time. Given that both countries implemented work and school restrictions, the increase in time spent at home can be attributed to the increase in household waste, which corroborates with the literature [41]. Both countries had a similar proportion of households with the majority indicating that municipal garbage collection services operate once a week. For Nigeria, the majority of households indicated a noticed change in the municipal collection services whereas the majority of households from Guyana indicated no change in the municipal services. In terms of recycling, Guyana had approximately $47 \%$ of households engaging in some sort of recycling activity whereas Nigeria had a relatively low proportion of approximately $17 \%$ of households engaged in recycling.

Households in both countries experienced multiple and differing changes in their solid waste management since the emergence of COVID-19. The findings corroborate with the evidence presented by Ikiza et al. [11] who found similar patterns in waste volume, recycling incidences and change in municipal services in Toronto, Canada. This evidence suggests similar waste management challenges are being faced globally amidst the pandemic regardless of the developmental status of the countries. Also, van Fan et al. [41] showed similar waste management challenges across China, the Czech Republic, and Singapore as a result of COVID19. The differences amongst countries will come from the household and municipal authorities' response to these challenges. To further expand on this dimension, Table 3 presents the binary LOGIT models that demonstrate the log odds of self-disposal of household waste given the changing dynamics of household solid waste management explored and expanded upon in Table 2.

The model diagnostics indicate good fitting models. The Hosmer and Lemeshow $p$ value indicates no evidence of a poor fit. The Cox and Snell R Square is a pseudo R square value indicating a model that is better fitting than the base LOGIT model alongside the Nagelkerke R Square which is an upper range $\mathrm{R}$ square value more aligned with the traditional linear model $\mathrm{R}$ square and gives the change in the dependent variable as explained by the regressors in the model [18]. Both R Square values show the model has an interpretive value from the regressors used. For both models presented, the practice of recycling yielded a statistically significant estimate with a negative relationship between recycling and self-disposal. This is not an unexpected finding and corroborates with the existing literature $[3,13,20]$. Aside from the recycling variable, the other exogenous factors varied in statistical significance between the two
Table 2 Characteristics of Household solid waste management since COVID-19

\begin{tabular}{lll}
\hline & Guyana & Nigeria \\
\hline Noticed increase in household waste since COVID-19 & $64.8 \%$ & $59.6 \%$ \\
Household waste volume doubled since COVID-19 & $45.7 \%$ & $50.1 \%$ \\
Noticed change in municipal waste collection services since COVID-19 & $23.6 \%$ & $63.9 \%$ \\
Municipal services scheduled once a week & $63.6 \%$ & $75.9 \%$ \\
Household engages in more recycling activities since COVID-19 & $46.8 \%$ & $16.5 \%$ \\
Households in data located in the most populous municipalities & $51.4 \%$ & $20.4 \%$ \\
Households in data with landfill or dumpsite in community & $28.2 \%$ & $30.4 \%$ \\
Households that engages in self-disposing since COVID-19 & $31.0 \%$ & $31.9 \%$ \\
\hline
\end{tabular}

Measured as a percentage frequency of the sample; the values reported represented the largest share of the sample 
Table 3 Binary logistic regression models on self-disposal of household waste

\begin{tabular}{lll}
\hline & Model 1 & Model 2 \\
\hline$\alpha$ & -0.434 & $1.904^{* *}$ \\
& $(0.341)$ & $(0.737)$ \\
Increase in household waste & 0.325 & $0.938^{* *}$ \\
& $(0.368)$ & $(0.293)$ \\
Change in collection schedule & $1.864^{* * *}$ & -0.335 \\
& $(0.378)$ & $(0.267)$ \\
Proximity to landfill & $0.688^{*}$ & -0.142 \\
& $(0.362)$ & $(0.234)$ \\
Practice recycling & $-0.724^{* *}$ & $-1.557^{* * *}$ \\
& $(0.341)$ & $(0.363)$ \\
Located in Georgetown & -0.486 & - \\
& $(0.341)$ & \\
Located in Lagos & - & $-0.942^{* * *}$ \\
& & $(0.415)$ \\
Located in Oyo State & - & 0.033 \\
Cox and Snell R Square & & $(0.312)$ \\
Nagelkerke R Square & 0.205 & 0.312 \\
Hosmer and Lemeshow & 0.299 & 0.438 \\
$p$ value & 0.523 & 0.615 \\
\hline
\end{tabular}

Model 1 presents the analysis for the LOGIT model for Guyana and Model 2 presents the analysis for the LOGIT model for Nigeria; values in () are the std. errors for the coefficients

*Indicates 10\% significance; the Cox and Snell and Nagelkerke R Square and Hosmer and Lemeshow test are goodness of fit diagnostic measures

**Indicates $5 \%$ significance

*** Indicates $1 \%$ significance

countries. For Guyana, the change in collection schedule and proximity to landfills were statistically significant in positively influencing a household engaging in self-disposal whereas in Nigeria, the increase in household waste positively influenced the households engaging in self-disposal. The difference in significant variables for the two countries is an indication of the unique underlying factors in the state of the solid waste management sector for each country and its impact of self-disposing. The literature showed that Nigeria generally has an issue with illegal dumpsites because of the quality of its waste collection services pre-COVID [1], so it would be expected that increasing household waste can lead to more instances of self-dumping as shown in the results. Even though no literature with empirical evidence for Guyana was sourced to fully outline issues on the prevalence of illegal dumping linked to the pre-COVID-19 condition of the waste management sector, this finding is an indication that the waste collection services frequency seems to be the dominating factor in the prevalence of self-dumping.

In terms of whether the location of the household in the largest municipalities was a factor, only households located in Lagos, Nigeria were positively impacted to engage in household self-disposal. The model's initial estimation shows the specific nature of the solid waste management issues due to COVID-19 in the country may vary in influencing self-disposal. Utilizing the model coefficients, the probability of the households engaging in self- disposal was computed by substituting the coefficient values from Table 3 into Eq. 3. For Guyana, households who experience a change in the municipal waste collection schedule due to COVID-19, there is a $12.9 \%$ probability that they will engage in self-dumping and if they live close to a landfill, the probability of self-dumping increases to $25.7 \%$. There is a $2 \%$ possibility that households who utilize recycling activities in Guyana will engage in self-dumping. For the households that experience a change in municipal waste collection services and engages in recycling activities, there is a $6.25 \%$ likelihood that they will engage in self-dumping. If they live near a landfill, this increases to a $12.4 \%$ likelihood that they will engage in self-dumping. The increase in solid waste in households was not a significant variable for Guyana. For Nigeria, households experiencing an increase in waste, there is a $34.3 \%$ likelihood that they will engage in self-dumping. The households in Nigeria that are experiencing waste and utilize recycling activities, there is a $7.1 \%$ chance of self-dumping. Interestingly, households in Lagos experiencing an increase in household waste are less likely to engage in self-dumping than in other municipalities with a probability of $13.4 \%$. For the households in Lagos who face increasing waste and utilize recycling activities, the probability of them engaging in self-dumping is $2.8 \%$. Proximity to landfills was not a significant variable for Nigeria. The statistics show that the increasing volume of waste and the corresponding household responses to this waste as waste collection services are restricted are positively contributing to the informal waste sector particularly for self-disposing. The households, especially for Guyana, have expressed their engagement in recycling. Even though the data were not gathered as to the composition of recycled material, the overall circumstances in the country as highlighted in the literature are that recycling is done informally either for small business purposes or for upcycling purposes [30, 47]. Though the informal recycling sector is shown to reduce the prevalence of self-dumping, the sector is unregulated and can be seen as a potential vector for COVID-19. More empirical research is needed on some of the dynamics of the informal recycling sector in the era of COVID-19, especially as a potential pathological channel.

\section{Conclusion}

Based on the analysis, both Guyana and Nigeria experienced impacts to their municipal solid waste management systems as a result of COVID-19; however, these impacts 
vary based on changes in the municipal waste collection schedules, proximity to landfills and recycling activities. The current solid waste management issues in response to COVID-19 are fostering more household self-disposing of waste and indirectly fostering the informal recycling sector. In Guyana, the change in waste collection schedules and the household's proximity to a landfill or dump are factors that increase the likelihood of the household self-disposing. In Nigeria, increasing household waste was the factor that increases the likelihood of households self-disposing. The empirical evidence shows that households for both countries who engage in recycling activities are less likely to engage in self-disposing.

Many potential new challenges are arising from the solid waste issues stemming from COVID-19. The models demonstrated that there are unique factors that policymakers need to consider in addressing the issue of self-dumping in the era of the COVID-19 pandemic. For Guyana, the change in schedules in response to pandemic has a positive impact on self-dumping which can shift the vulnerability of contracting COVID-19 to the households. The policymakers in Guyana need to consider more safety measures for waste collectors and return to a regular schedule with sterner safety protocols. In Nigeria, household increase in solid waste since the COVID-19 pandemic is the main contributing factor to persons self-dumping. Nigeria should consider waste reduction strategies primarily through public education or consider waste reduction incentive programs, such as deposit fees for waste materials, though the latter may be a strategy for the overall development of the waste management sector in both countries given challenges of the sector pre-COVID-19 highlighted in the literature. Recycling did show to have an inverse effect on illegal dumping, an effect similar to what is documented in the literature. Despite this result, recycling in the countries is not properly regulated and limited in infrastructure. There is also very limited recycling incentives programs to encourage the practice.

The reduction in collection services and increasing household waste will lead to clustered roadside bins with potentially contaminated waste. The potential increase in self-disposing at the household level in response can lead to increased risk in spreading COVID-19, especially if dumping activities are unregulated. Even with the activities of re-use, recycling or upcycling of materials which are done informally in both countries can lead to potential contagion spread given the lifespan of COVID-19 on surfaces. More research is needed in better understanding the environmental and epidemiological aspects of COVID-19 and the sub sequential changes in solid waste management. The informal waste sector especially the issue of self-disposal and informal recycling adds a new dimension for policymakers to consider in managing COVID-19. The evidence from Guyana and Nigeria highlights the need for the municipal solid waste management system to re-think their approach to solid waste in the era of COVID-19. More support and resources are needed to educate, facilitate and support communities as COVID-19 changes the dynamics of their household waste disposal.

Authors contribution Conceptualization: SM; Methodology: SM, TDTO, NA; formal analysis and investigation: SM; writing-original draft preparation: SM, D-MR-M; writing - review and editing: TDTO, TO, OK, AF; funding acquisition: N/A; resources: TDTO, NA, SM; supervision: TDTO.

\section{Declarations}

Conflict of interest The authors declare that they have no known competing financial interests or personal relationships that could have appeared to influence the work reported in this paper. The nature of this research was not done with animals, vulnerable groups or in an invasive manner. The research was done in full confidentiality with voluntary participants.

\section{References}

1. Afon AO (2007) Informal sector initiative in the primary sub-system of urban solid waste management in Lagos. Nigeria Habitat International 31(2):193-204. https://doi.org/10.1016/j.habitatint. 2007.02.007

2. Agamuthu P, Barasarathi J (2020) Clinical waste management under COVID-19 scenario in Malaysia. Waste Manage Res. https://doi.org/10.1177/0734242X20959701

3. Aizawa H, Yoshida H, Sakai S (2008) Current results and future perspectives for Japanese recycling of home electrical appliances. Resour Conserv Recycl 52(12):1399-1410. https://doi.org/10. 1016/j.resconrec.2008.07.013

4. Aparcana S (2017) Approaches to formalization of the informal waste sector into municipal solid waste management systems in low- and middle-income countries: review of barriers and success factors. Waste Manage 61:593-607. https://doi.org/10.1016/j.wasman.2016.12.028

5. Berger D (2017) Introduction to binary logistic regression and propensity score analysis. Research Gate Publication. https:// www.researchgate.net/publication/320505159_Introduction_to_ Binary_Logistic_Regression_and_Propensity_Score_Analysis.

6. Boucher J, Billard G (2019) The challenges of measuring plastic pollution. Field Actions Science Reports, SI19:68-75. IUCN, Review of Plastic Footprint Methodologies. http://portals.iucn. org/library/sites/library/files/documents/2019-027-En.pdf.

7. Cecilia T (2012) Urbanization, gender, and urban poverty: paid work and unpaid care work in the city. international institute for environment and development: United Nations population fund. http://pubs.iied.org/10614IIED.html.

8. Chen Y, Guo C (2020) Handbook of emergency disposal and management of medical waste in china. El Sevier Public Health Collection. http://bcrc.tsinghua.edu.cn/col/1256347643949/2020/ 06/22/1592834394326.html.

9. Gujarati D, Porter C (2009) Basic econometrics. McGraw-Hill Irwin, Pennsylvania

10. Ichinose D, Yamamoto M (2011) On the relationship between the provision of waste management service and illegal dumping. Resour Energy Econ 33(1):79-93 
11. Ikiz E, Maclaren VW, Alfred E, Sivanesan S (2020) Impact of COVID-19 on household waste flows, diversion and reuse: the case of multi-residential buildings in Toronto, Canada. Resour Conserv Recycl. https://doi.org/10.1016/j.resconrec.2020.105111

12. Kulkarni BN, Anantharama V (2020) Repercussions of COVID19 pandemic on municipal solid waste management: challenges and opportunities. Sci Total Environ. https://doi.org/10.1016/j. scitotenv.2020.140693

13. Kuo Y-L, Perrings C (2010) Waste time? Recycling incentives in urban Taiwan and Japan. Environ Resource Econ 47:423-437. https://doi.org/10.1007/s10640-010-9386-1

14. Liu Y, Kong F, Santibanez Gonzalez EDR (2017) Dumping, waste management and ecological security: evidence from England. J Clean Prod 167:1425-1437. https://doi.org/10.1016/j.jclepro. 2016.12.097

15. Low DW, Koh A (2020) Singapore's food delivery surge during lockdown highlights waste problems. Bloomberg News. www.bloomberg.com/news/articles/2020-06-24/singa pore-binges- on-plastics-ordering-food-during-virus-lockdown.

16. Marshall RE, Farahbakhsh K (2013) Systems approaches to integrated solid waste management in developing countries. Waste Manage 33(4): $988-1003$

17. Matsumoto S, Takeuchi K (2011) The effect of community characteristics on the frequency of illegal dumping. Environ Econ Policy Stud 13:177-193

18. Mbachu HI, Nduka EC, Nja ME (2012) Designing a pseudo R-Squared goodness-of-fit measure in generalized linear models. J Mathematics Research. https://doi.org/10.5539/jmr.v4n2p148

19. Mmereki D, Bladwin A, Li B (2016) A comparative analysis of solid waste management in developed, developing and lesser developed countries. Environ Technol Rev 5(1):120-141. https:// doi.org/10.1080/21622515.2016.1259357

20. Moh YC, Manaf LA (2014) Overview of household solid waste recycling policy status and challenges in Malaysia. Resour Conserv Recycl 82:50-61. https://doi.org/10.1016/j.resconrec.2013. 11.004

21. Mukama T, Ndejjo R, Musoke D, Musinguzi G, Halage AA, Carpenter DO, Ssempebwa JC (2016) Practices, concerns, and willingness to participate in solid waste management in two urban slums in Central Uganda. J Environ Public Health. https://doi.org/ $10.1155 / 2016 / 6830163$

22. Narayana T (2009) Municipal solid waste management in India: from waste disposal to recovery of resources. Waste Manage 29(3):1163-1166. https://doi.org/10.1016/j.wasman.2008.06.038

23. Nghiem LD, Morgan B, Donner E, Short MD (2020) The COVID19 pandemic: considerations for the waste and wastewater services sector. Case Stud Chem Environ Eng. https://doi.org/10.1016/j. cscee. 2020.100006

24. Nzediegwu C, Chang SX (2020) Improper solid waste management increases potential for COVID-19 spread in developing countries. Resour Conserv Recycl. https://doi.org/10.1016/j.resco nrec.2020.104947

25. Nzeadibe TC (2009) Solid waste reforms and informal recycling in Enugu urban area. Nigeria Habitat International 33(1):93-99. https://doi.org/10.1016/j.habitatint.2008.05.006

26. Nzeadibe TC, Ejike-Alieji AUP (2020) Solid waste management during Covid-19 pandemic: policy gaps and prospects for inclusive waste governance in Nigeria. Local Environ 25(7):527-535. https://doi.org/10.1080/13549839.2020.1782357

27. Nzeadibe TC, Madu I (2012) Open dump. In: Zimring CA, Rathje WL (eds) Encyclopaedia of consumption and waste: the social science of garbage. SAGE Publications Inc., California, pp 632-634. https://doi.org/10.4135/9781452218526.n242

28. Oguntoyinbo OO (2012) Informal waste management system in Nigeria and barriers to an inclusive modern waste management system: a review. Public Health 126(5):441-447. https://doi.org/ 10.1016/j.puhe.2012.01.030

29. Ogwueleka T (2009) Municipal solid waste characteristics and management in Nigeria. Iran J Environ Health Sci Eng 6(3):173-180

30. Oyedotun TTD, Oluwasinaayomi FK, Famewo A, Oyedotun TD, Moonsammy S, Ally N, Renn-Moonsammy D-M (2020) Municipal waste management in the era of COVID-19: perceptions, practices, and potentials for research in developing countries. Research in Globalization 2:1-10. https://doi.org/10.1016/j.resglo.2020. 100033

31. Paul JG, Arce-Jaque J, Ravena N, Villamor SP (2012) Integration of the informal sector into municipal solid waste management in the Philippines-what does it need? Waste Manage 32:20182028. https://doi.org/10.1016/j.wasman.2012.05.026

32. Pentaeado CSG, Soares de Castro MA (2021) Covid-19 effects on municipal solid waste management: what can effectively be done in the Brazilian scenario? Resour Conserv Recycl. https://doi.org/ 10.1016/j.resconrec.2020.105152

33. Rajmohan KVS, Ramya C, Viswanathan MR, Varjani S (2019) Plastic pollutants: effective waste management for pollution control and abatement. Curr Opin Environ Sci Health 12:72-84

34. Riquelme R, Méndez P, Smith L (2016) Solid waste management in the caribbean-proceedings from the caribbean solid waste conference. Technical Note No. IDB-TN-935. https://publicatio ns.iadb.org/publications/english/document/Solid-Waste-Manag ement-in-the-Caribbean-Proceedings-from-the-Caribbean-SolidWaste-Conference.pdf.

35. Saadat S, Rawtani D, Hussain CM (2020) Environmental perspective of COVID-19. Sci Total Environ. https://doi.org/10.1016/j. scitotenv.2020.138870

36. Sembiring E, Nitivattananon V (2010) Sustainable solid waste management toward an inclusive society: integration of the informal sector. Resour Conserv Recycl 54(11):802-809. https://doi. org/10.1016/j.resconrec.2009.12.010

37. Sedova B (2015) On causes of illegal waste dumping in Slovakia. J Environ Plan Manag 59(7):1277-1303

38. Seunghae L, Hae Sun P (2011) Korean household waste management and recycling behaviour. Build Environ 46:1159-1166

39. Singh N, Tang Y, Zhang Z, Zheng C (2020) COVID-19 waste management: effective and successful measures in Wuhan, China. Resour Conserv Recycl 163:10-11. https://doi.org/10.1016/j.resco nrec.2020.105071

40. van der Werf P, Cook R, Hargreave P, (2020) Summary of finding related to COVID-19 impacts on waste flows: Week of April 27, 2020. Ontario Waste Management Association, Brampton, Ontario. https://www.owma.org/cpages/covid.

41. van Fan Y, Jiang P, Hemzal M, Klemes JJ (2020) An update of COVID-19 influence on waste management. Sci Total Environ 754(1):1-6. https://doi.org/10.1016/j.scitotenv.2020.142014

42. Villalba L (2020) Recent evolution of the informal recycling sector in Argentina within the 'popular economy': measuring its impacts through a case study in Tandil (Buenos Aires). Waste Manage Res 38(9):1037-1046. https://doi.org/10.1177/07342 X20938437

43. Wilson DC, Velis C, Cheeseman C (2006) Role of informal sector recycling in waste management in developing countries. Habitat Int 30(4):797-808. https://doi.org/10.1016/j.habitatint.2005.09. 005

44. Yang W, Fan B, Desouza C (2019) Spatial-temporal effect of household solid waste on illegal dumping. J Clean Prod 227:313-324

45. Yousif DF, Scott S (2007) Governing solid waste management in Mazatenango, Guatemala: problems and prospects”. Int Dev Plan Rev 29(4):433-450. https://doi.org/10.3828/idpr.29.4.2 
46. Zaiontz C (2021) Logistic regression sample size. Real statistics using Excel. https://www.real-statistics.com/logis tic-regression/logistic-regression-sample-size/logistic-regre ssion-sample-size-binary/.

47. Zavodska A, Knight J (2002) A practical approach to future municipal solid waste management in developing countries-a closer look at Georgetown, Guyana. J Solid Waste Technol Manag 35(3):162-168. https://doi.org/10.5276/JSWTM.2009.162
Publisher's Note Springer Nature remains neutral with regard to jurisdictional claims in published maps and institutional affiliations. 